\title{
We might get a lot from a province-wide colon screening program, but maybe not peace of mind
}

$\mathrm{S}$ everal years ago my friend Kathy approached her doctor about getting a screening colonoscopy. Although concerned about unnecessary testing, she was aware that there was a history of colon cancer in her family - her sister had died in middle age of the disease.

Kathy read the research, which showed that in most cases colon cancer starts as polyps, and when these are found by colonoscopy and removed before they become malignant, lives can be saved. Because of her "highrisk" status, her procedure was subsidized by the public purse.

Kathy's colonoscopy went well, but some people may bleed from the procedure, suffer ill effects from the purgatives or, in extreme cases, end up in surgery with a perforated bowel.

Like all screening programs, colon screening is imperfect and surrounded by vigorous debate about how effective it is in preventing lethal colon cancer. There is a "substantial and variable polyp miss rate, even among expert examiners who know that they are being scrutinized." There is also a stark fact of life: at least one-third of healthy people between 50 and 75 will have colon polyps and if these are left untreated most of us would be none the wiser. But if we seek, we shall find.

When British Columbia's new Provincial Colon Screening Program, consisting of a $\$ 35$ fecal immunochemical test (FIT) offered to all eligible residents, was unrolled on Vancouver Island in the spring of 2013, referrals to gastroenterologists on the island tripled. The ensuing wait-lists for a colonoscopy were bad enough to generate front-page headlines in the Vancouver Sun. Clearly nothing invigorates journalists more than the hint that Canadians are being made to wait for something life-saving.

Last spring, I asked the BC author-

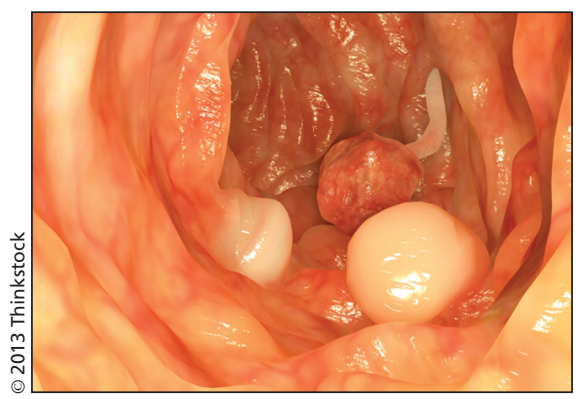

ities about the forthcoming screening program, wondering how many people would be screened, how many lives would be saved and how much all this would cost. The answers (I'm summarizing here) were pretty uniform: "It depends." It depends on how many islanders take the trouble to scoop a poop sample into a bottle, how many samples are abnormal and how many people will book a colonoscopy after an abnormal test. As for cost? That also depends.

Most of us who enter medical screening programs are unaware of one simple fact: our lives may be drastically altered in ways that are impossible to anticipate. If and when polyps are found, people may wear a "precancerous" label for the rest of their lives, and be frequently reminded of the risk to their colon health because of requests for frequent followup colonoscopies by their physicians.

The FIT test seems sensible as a first type of screening test, and yet seeing that there is no evidence from any randomized controlled trial showing that colonoscopy every 10 years is any better than FIT every year in reducing colon cancer death, why does the perception persist that colonoscopies are superior for screening? It's likely because the removal of polyps at the time of screening seems so satisfying, even if it turns many people into lifelong polyp-fearing patients.

Because many of us will have polyps, and very few of us will die from them, the concept of overdiagnosis raises its ugly head. The medical world is starting to recognize this, and a recent JAMA editorial proposed a major rethink of terms like "cancer," saying we should reserve our use of that word for "describing lesions with a reasonable likelihood of lethal progression if left untreated."' Is it possible that automatically naming colon polyps "precancerous" is a misnomer that could lead to overdiagnosis and overtreatment?

No doubt there are strong incentives, financial and other, shaping public and professional opinion on who should be screened, how often and for what purpose. Incentives to do short, relatively well paying colonoscopies means that demand for gastroenterologists will rise (and the new long wait lists prove this) and some of that expected demand will be dealt with in the private system, where gastroenterologists are better paid. This is becoming evident as the new public colon-screening program in $\mathrm{BC}$ takes off. Is our program going to be funding platoons of polyp police, incented to hunt down and eradicate the tiny mushrooms sprouting in our colons? Inevitably, yes. Will lives be saved? Undoubtedly, yes. Will lives be altered and many more of us find it that much more difficult to book a visit with a gastroenterologist when we are genuinely sick? That, sadly, seems a big and troublesome "yes" as well.

\footnotetext{
Alan Cassels MPA

Drug-policy researcher and author

University of Victoria

Victoria, BC

\section{References}

1. Young PE, Womeldorph CM. Colonoscopy for colorectal cancer screening. J Cancer 2013;4:217-26

2. Esserman LJ, Thompson Jr. IM, Reid B et al. Overdiagnosis and overtreatment in cancer: an opportunity for improvement. JAMA 2013;310:797-8.
}

CMAJ 2013. DOI:10.1503/cmaj.131348 